\title{
01
}

\section{SETTING THE STAGE}

\author{
Josefine Fokdal, Olivia Bina, Prue Chiles, Liis Ojamäe and Katrin Paadam
}

\section{Introduction}

The motivation for writing this book stems from our engagement with three undeniable trends in the twenty-first century: a geographical trend of escalating urbanisation in a world shaken by multiple interdependent crises, a political trend of recognising the challenges following from this and placing them centrally into global plans for sustainable development, and thirdly, a trend in science policy of proclaiming the importance of interdisciplinary and transdisciplinary (ITD) research, not least to inform policymaking. While torn between challenges and opportunities, one aspect that seems to unite all urban sustainability agendas is an appeal for transformative change and for knowledge that can make it happen. Our collaborative book, Enabling the City, occupies this inconvenient, uncomfortable, inarticulate space - but a space almost universally acclaimed as necessary to solve the difficult processes and urban challenges of today. This book focuses on how inter- and transdisciplinary processes of knowledge production may contribute to transformation at a local level, inescapably influenced by global trends.

\section{Urbanisation}

Today's processes of urbanisation and the significant projected growth and shift of dynamic urbanisation to the South and East all imply complex challenges related to urban development (UN-Habitat, 2006, 2011; Herrle et al., 2015). Urban areas represent approximately $2 \%$ of land cover in the world but produce $70 \%$ of emissions (world cities account for between $60 \%$ and $80 \%$ of energy consumption), and are notorious for their unsustainable ecological footprints. In 2014, 72.5\% of the population of Europe lived in urban areas, and this figure is still rising.

FIGURE I.1.1 Kew Gardens. Photo by Olivia Bina. 
Case studies and stories in this volume from around Europe, set in cities and towns of different sizes and profiles, illustrate the familiar trend towards a diminishing urban-rural divide and the growth of suburban and peri-urban areas on the outskirts of metropolitan regions. Social, economic and environmental problems overlap, often dramatically, within urban areas worldwide (Satterthwaite \& Bartlett, 2016).

A global transformation in the way we live and work is urgently needed, and the projected world population of nine billion in 2050 means that "business as usual" is no longer an option (Cornell et al., 2013). We need to end the insanity of continuous economic growth leading to the inevitable the overconsumption of finite resources (New Economics Foundation, 2009, p. 3). This requires a fundamental change of cultural dispositions linked to consumption patterns and lifestyles, especially in developed countries. Invariably, the processes of urbanisation entail a complex set of trade-offs and synergies between environmental, social and economic aspects of development that cannot be constrained within thematic, sectoral or disciplinary silos (Sachs et al., 2019). The past decades have, among others, shown that both in practice and academic research closer cooperation between various actors is necessary to understand and impact the ongoing urbanisation processes.

\section{Setting a Global Agenda for Sustainable Development}

As a result of the global significance of urban trends, the sustainable development agenda is also changing to reflect this priority - through goal-driven changes. The UN 2030 Agenda called "Transforming our World" asks for a "transformative development pathway" (ICSU \& ISSC, 2015, p. 9), and the many debates about science and knowledge needed to address twenty-first-century challenges also appeal to the need for significant transformations in education and research (Wernli \& Darbellay, 2016). In particular, the German Advisory Council on Global Change ${ }^{1}$ distinguishes between transformation research, exploring "the factors, mechanisms and causal relationships of transformation," and transformative research, referring to "the kind of research that supports the transformation by means of specific innovations - be they social, economic, technical or of some other kind" (WBGU, 2016, p. 34). New approaches in urban research and practice and new forms of governance and decision-making, however, need new modes of knowledge production as a means for coping with the challenges of a more sustainable urban future.

The 17 Sustainable Development Goals (SDGs), along with other global frameworks such as the Paris Agreement, are rather ambitious in their striving for more sustainable development. ${ }^{2}$ Goal 11, for example, to make cities and human settlements inclusive, safe, resilient and sustainable, identifies ten targets. ${ }^{3}$ No. 3 is especially relevant to the work discussed here: "By 2030, enhance inclusive and sustainable urbanization and capacity for participatory, integrated and sustainable human settlement planning and management in all countries" (UNGA, 2015). Throughout this book, we argue that capacity for such "participatory, integrated and sustainable" planning, can best be enabled through knowledge that is both inter and transdisciplinary. Translating these agendas, given the trends and challenges we have "on the ground," we need to create new systems, models and paradigms that will work in favour of the well-being of people living in cities. We need new knowledge that will reach various actor groups and ways of producing knowledge based on engagement in order to learn how to "enable the city" to thrive and cater for a more sustainable urban future. In other words, urban sustainability entails fundamental change, embracing the fact that knowledge production should be seen as an inclusive process that is not limited to academia and its ways of knowing. 


\section{Defining Inter- and Transdisciplinary Processes}

Our exploration of inter- and transdisciplinary (ITD) approaches to the design and application of knowledge ${ }^{4}$ focuses on urban research and practice that contribute to the United Nations sustainability agenda. Inter- and transdisciplinary approaches are an expression of depth and degrees of collaboration and diversity, and debates around their need are premised on fundamental questions about the nature and legitimacy of knowledge: what it is, who holds it and who is entitled to contribute to its production.

The definition and common understanding of interdisciplinarity, and related ideas of "multi-" and "trans"disciplinarity, all remain contested and tend to be superficial rhetoric rather than conceptual clarity (see also Chapter IV.1). ${ }^{5}$ These three concepts all pertain to the idea of linking disciplines for the purpose of researching complex problems; however, their purpose and reach is fundamentally different (Lang et al., 2012).

Building on the work done by Wernli and Darbellay (2016) and Petts et al. (2008), we understand interdisciplinarity as an approach that can help to structure multiple sources of knowledge around a common topic, promoting the exchange of disciplinary expertise through cooperation, respect and the willingness to learn from, and to understand, each other. We also give our own definition in Chapter I.3. This requires an openness on the part of collaborating disciplines (Mendes \& Sá, 2017), and a recognition of shared values and trust between individuals of different disciplinary backgrounds (see also Chapter II.6). It also entails mutual curiosity towards other knowledge cultures (see also Chapter II.3), and even the willingness to give up some disciplinary territory. ${ }^{6}$

The recent debates assert to be about the promotion of interdisciplinarity in view of a response to a better understanding of problems or as a means of generating questions around which new forms of thought and experimental practice can coalesce (Barry \& Born, 2013, p. 10; see also Chapters II.5 and II.8). However, although interdisciplinarity is increasingly central to research agendas, and recognised as a precondition for sustainability (Porter \& Rafols, 2009; Sterling, 2004; van Rijnsoever \& Hessels, 2011), its effective implementation in research projects remains the exception (Owens et al., 2006; Wernli \& Darbellay, 2016) to the rule. Genuine progress towards greater unity of knowledge is often marginalised in practice: actual projects and agendas rarely live up to the lofty promises. Cooperation in producing knowledge is uneven and weak in its ability to shift research agendas towards a new comprehensive approach to research (Petts et al., 2008). Deep-rooted divisions between disciplines lead to an incomplete understanding of global changes affecting human societies (UNESCO \& ISSC, 2010). Active collaboration, including knowledge exchange, remains rare to date (Stokols, 2014), largely due to the transaction costs involved and the lack of incentives in both practice and academic arenas.

We use Hoffmann-Riem et al. (2008, p. 4) for an approach to Transdisciplinarity that calls for different types of knowledge production for social change. Firstly, through grasping the complexity of a problem and questioning the normative nature of knowledge production; secondly, by recognising the gap between the perceived problem in science and practice; and thirdly, by producing knowledge for the "common good." Even clearer is the desire, indeed the necessity, for transdisciplinary work, and thus to open the process of urban knowledge production to a wide range of actors that have an interest in city-making beyond academics and so-called specialists. ${ }^{7}$

Transdisciplinarity, ${ }^{8}$ as we understand it, includes the integration of knowledge from various disciplines (i.e. interdisciplinarity) as well as the involvement of civil society and other non-academic actors into the realm of research and practice. The aim is to produce more suitable and applicable results for policymaking and societal change (e.g. Polk, 2014, 2015; Klein et al., 2001). At a local 
scale, it can contribute to transforming urban neighbourhoods into accessible, creative, engaging and living spaces by interactive strategies enhancing participation of inhabitants and various stakeholder groups (see also Chapters II.1, II.2, II.4 and II.9). However, the challenge of overcoming researcherdriven projects and an uneven balance of ownership (Pohl et al., 2010; Lang et al., 2012), along with issues of communication, time-consuming processes and the fact that reliability of knowledge is sometimes compromised for the sake of accountability (Polk, 2014, p. 441), are some of the core obstacles to transdisciplinarity identified in the discourse (see also Chapter II.7). Thus, despite the trend in science governance in particular of proclaiming the importance of interdisciplinary and transdisciplinary research, there are still many obstacles to overcome.

\section{The Transformative Power of Inter- and Transdisciplinary Research and Practice in the Urban Realm}

The urban environment provides an excellent arena for exploring the multiple challenges and obstacles of integrating diverse sources of knowledge, from multiple disciplines and actors, in an attempt to make sense of deeply interconnected and interdependent problems and solutions, both theoretical and practical, that will enable transformation (see chapter IV. 3 in this volume). ${ }^{9}$

Inter- and transdisciplinary urban research and practice, and particularly urban planning, has a long tradition of knowledge integration, although under different labels such as real-world laboratories (e.g. Schäpke et al., 2017), using experiments as the main mode of knowledge production (e.g. WBGU, 2014; Schneidewind \& Singer-Brodowski, 2014), participatory action research (e.g. Bradbury \& Reason 2003) and transition research (e.g. Van de Bosch \& Rotmans, 2008), just to mention a few. Within the field of urban planning practice, there is a tradition of participatory approaches that is worthwhile to build upon when conducting inter- and transdisciplinary research: for example, collaborative planning (Healey, 1997), the communicative turn (Healey, 1993), participatory planning (Chambers, 1998; Goethert, 2004) and community action planning (Hamdi \& Goethert, 1997). Within planning practice, inclusive governance and participation ${ }^{10}$ has become a cornerstone in the global South and North (UN-Habitat \& UN-ESCAP, 2008; UN-Habitat \& GLTN, 2009).

Participation is understood as plurality of decision-making, involving multiple actors, including an organized civil society, and a readiness to negotiate and compromise are seen as necessary means for successful interaction (Benz and Papadopoulous 2006). In most cases, however, participatory processes are "owned" and driven by (local) government institutions as the legitimate representatives of the state and participation is expected to provide a "bottom-up" input to formal systems (Chakraborty 2012). Mosse (2001) further identified the danger of external stakeholders setting the local agenda in a more implicit manner under the label of including local knowledge through participation (Cooke and Kothari 2001). Participatory formats that have been developed vary widely, depending, on the one hand, on the political opportunity structure in a particular context, such as the strength and willingness of the local political system to cooperate; and, on the other hand, on the resources and capacities of civic groups to engage in "negotiating development" (Roy 2009, p. 166). Also, the tradition in planning is specific in terms of culture relating to particular societal histories.

The experience and knowledge within the urban realm could be better integrated into the more recent discussion on transdisciplinarity and transformative science for a more sustainable future. There is much to be learned from failures and limitations encountered in practice and research within the urban realm and the development context. Often processes are messy, complex, difficult and time-consuming, and there is a large risk of failure. The kind of knowledge produced through 
these processes, however, is what we need in order to be able to localise the Sustainable Development Goals and the New Urban Agenda (NUA), as this book shows.

\section{An Overview}

Building on the experience of the authors, ${ }^{11}$ this book describes intellectual and practical projects carried out in a different way, where transdisciplinary urban issues have enabled new knowledge and ways of knowing, as well as accounting for persistent challenges and, at times, failures. It aims at enabling new knowledge for sustainable futures in order to enhance the quality of life in cities by demonstrating the use and value of crossing borders between disciplines and beyond academia.

\section{Part I: "Setting the Scene"}

Part I, "Setting the Scene," introduces the work, as above, and discusses the journey the editors and authors have taken. Bina et al. present a comprehensive framework that arises from an analysis of case studies in Part II, providing a unique overview of possible ways of knowing and of enabling new knowledge. It proposes four phases of inter- and transdisciplinarity, and four enabling conditions and qualities that are crucial for inter- and transdisciplinary processes, highlighting aspects of learning, competences and dispositions. Mennes then presents a baseline vocabulary that guides the reader with a useful series of definitions that cross disciplines and makes the publication applicable to a broad readership.

In this way, Enabling the City makes a contribution towards the kind of transformative research and practice required to address twenty-first-century urbanisation challenges, with their complex multisectoral interdependencies, captured by the Sustainable Development Goals, and their overarching need for greater collaborative ethos, integrative knowledge production and practices. Parts II and III also reflect on different research and practice cultures - a mirroring of what is going on in inter- and transdisciplinary urban processes.

\section{Part II: "Urban Stories Beyond Disciplines"}

In Part II, "Urban Stories Beyond Disciplines," the individual chapters explore aspects of inter- and transdisciplinarity through critical themes (e.g. ageing, health and dementia, energy production, mobility cultures, heritage, housing, re-use and renewal of buildings and public spaces) that need to be addressed in innovative ways in order to contribute to a more sustainable urban future.

Most started their life as case studies presented and analysed during the course of our meetings and events over four years in different countries with the INTREPID network. They show different aspects of the framework that we introduce in Part I, experienced in a variety of contexts and scales.

The first chapter by Chiles et al. builds around a collaborative and transdisciplinary project in Stockbridge, South Yorkshire, with the aim of looking into a new energy future for the town and how this could be at the heart of all sustainable renewal in the town. The process involved local residents and an interdisciplinary academic team including an embedded ethnographer who "facilitated" the self-reflexivity and, more critically, better communication among the public and academic team members during the project. In this process, the value of establishing a common language, the continuous engagement over a longer time period (a strong element of "social" time) and the recognition of the local context, i.e. the history of the place, were strong enabling factors. 
The second chapter, "A Creative 'NanoTown': Framing Sustainable Development Scenarios with Local People in Calabria, Italy," by Verdini et al., aims to enable a transition towards sustainability for a town affected by economic and demographic decline in a rural area in southern Italy. An international workshop, initiated by the elected politicians, acted as a catalyst for a positive atmosphere for change. Also, interdisciplinary students acted as individual "change agents" at the same time, building capacities and empowering through shared learning experiences. This case study illustrates the three phases, co-design, co-production and continuation, as well as the issue of competences: "The Gagliato experience has helped to refine a working process and a set of competences, which are replicable and may be incorporated into university urban curricula." Also, it becomes evident here that context matters in the sense that the political will was there and the citizens were engaged in the new vision for the town.

The third chapter, by Gromark et al., is a reflection on an inter- and transdisciplinary process from its very beginning to implementation (which is often not present in other case studies). The aim of the process was to create a research-informed sustainable residential project. The project itself experiments with cooperative rental housing (in physical, architectural and technological forms), which moves beyond the rather technocratic understanding of sustainability at the housing scale. It shows the value of disseminating the lessons learned through a platform for mutual learning and exchange of good practice. The authors point towards three enabling conditions for the inter- and transdisciplinary process: firstly, the continuity of the individuals involved in the process; secondly, the mandates of the people involved were never questioned; and thirdly, the value of different knowledge and competences by people involved was recognised by everyone. In addition, mutual trust and a "distinct common culture of commitment to the cause" was built up during meetings every second month over eight years - so again, time matters!

Also on the building scale, but around a public institution, the chapter by Wolf et al. is an illustration of accompanying research on how the city initiated and supported a new creative hub in the former public pool in the city of Lucerne. Trust and spatial proximity and a history of working together previously are identified as key enabling conditions: "They were aware of the challenges of interand transdisciplinary research projects regarding joint knowledge production, and they regularly reflected on this." Again, the reintegration of knowledge through dissemination demonstrated difficulties, and it was only through the involvement in the INTREPID network that publication of the research was made possible.

The aim of the inter- and transdisciplinary process presented by Dietz et al. in Chapter 5 of Part II was to push for changes towards a sustainable mobility culture in Stuttgart, Germany. The specific project presented is on "parklets" - the occupation of a parking spot for three months to create awareness and start a dialogue around the quality of urban space once the parking spot was converted. Data collection and mutual learning processes were recognised as part of capacity building for all actors involved in the inter- and transdisciplinary process, which led to a rethinking of the future planning of the public space. This would have been impossible without the available resources in terms of human capacities, a change agent, time and flexible funding.

In a similar manner, the chapter "A Step Towards an Enjoyable City: Joining Expertise in Redesigning Public Space Along the 'Main Street' in Tallinn” by Paadam and Ojamäe describes an inter- and transdisciplinary process in relation to moving towards more inclusive research-based planning in Tallinn aimed at establishing a dialogue within the city around the development of the quality of urban public space. At the potential advent of a new planning culture, although in a slowly changing difficult political landscape (context), it showcases a "paradigm shift" in architects' and planners' approach. Based on the project leaders' growing awareness and acknowledgement of the 
usefulness of a wider scale of disciplinary competences in the production of in-depth knowledge, the multiple studies initiated provided essential input to architectural competitions and discussions at City Forums. The chapter also self-critically reflects on an experiential experience of architects and sociologists joining in an inter- and transdisciplinary qualitative research process, which, aside from mutual advancement, also inspired the business actors involved to initiate and fund even further discussion occasions on the future of the city centre (continuation). The chapter underscores the importance of facilitating learning "by allowing research-informed imagination of the possible," the willingness and capacity to engage with the unknown in order to push for "transformative change" within society and ways of creating the quality of urban space.

The case study presented by Dimitrova discusses a "top-down" approach to turn a neighbourhood in Sofia, Bulgaria, into a Creative Industries area through a focus on cultural heritage and the preservation of a certain neighbourhood culture. It is a clear illustration of the issue of time as it is lived in different "communities" - practice versus academia - but also of the time constraints within academia and funding schemes. Also, the fact that words matter is well illustrated in this chapter. Building on a certain level of frustration, a process of self-reflection was initiated to enhance the learning experiences among the involved actors.

Chapter 8 in Part II illustrates different types of knowledge the authors Andersen and Kirkeby identified around building homes for people with dementia: "Context-independent knowledge is probably easier to transport with only minor changes in content whereas context-dependent knowledge requires more interpretation and personal acquisition." Building on work by Latour, they establish what they call "flexible knowledge." This does not imply "that 'anything goes,"” but highlights that knowledge, as contextbased knowledge, is not independent of place or circumstance; it has to be related to specific situations. This case study is a robust account of aspects of leadership within a transdisciplinary process.

The last chapter in Part II, by Nikšič, discusses more inclusive urban planning approaches in Ljubljana, Slovenia, and is an excellent showcase of how trust needs to be built between different stakeholders but also of trust in the state as an actor that facilitates participatory planning approaches. This is something that is often overlooked in global agenda-setting (the Sustainable Development Goals) and where the local context needs flexibility and adaption. The chapter reflects on the approach and willingness to change strategy and adapt unusual approaches to reach different target groups. In addition, strong leadership, "combined with vision and operational strategy" was a major enabling factor in facilitating the process.

\section{Part III: "Short Stories from Practice"}

Part III "Short Stories from Practice" complements the focus on research in Part II by adding the perspectives of practitioners on ITD processes in which they have been involved over shorter or longer time periods. Some practice stories can be seen as different sides of the coin of the same case study presented in Part II. We felt that adding the practice perspective on ITD processes would enrich the "thick descriptions" in Part II and make this volume more applicable for a larger audience. Within the field of architecture and urban planning, there is a long tradition of facilitating participatory and collaborative processes that we found critical to build on in the book.

The first practice story in Part III by Heslop, "Protohome," targets the phenomenon of homelessness in the context of the UK. While this practice story showcases many aspects of our threedimensional framework, the aspect of self-reflection as part of a social learning process is key. 
"Portland Works - Sheffield," written by Cristina Cerulli, discusses a campaign initially focused on opposing the immediate threat - the redevelopment of the building; it quickly shifted towards being a propositional endeavour, with tenants, activists, local residents, practitioners and academics working together to propose viable alternatives, rather than simply opposing the change of use.

The cooperative housing project "Spreefeld" in Berlin, Germany, is based on an interview with Michael LaFond, one of the co-founders of this socially sustainable and ecologically driven project. Challenges of collaboration and decision-making processes are put into the contextual perspective of an increasing neo-liberal setting in Berlin ten years from the project's completion. According to Lafond, this would not have been possible in today's Berlin - thus, context matters!

Three of the practice stories complement and are based in the same places as Chapters 5, 9 and 12 in Part II. The practice story in Gagliato, Calabria, by Wills et al., describes the next stage of the process where final-year architecture students and newly qualified architects develop a strategy for renewal used for a successful bid to the local government. Around the topic of tourism in a rural and declining town in southern Italy, the involvement of students in a shared learning process in the specific context shows the importance of including specific skills and competences into the urban curricula to educate the future generation of architects and planners.

The "City Forums" in Tallinn by Järg, with a wide number of participants, is a nice illustration of the changing roles of architects and urban planners and showcases how much context matters in terms of political willingness and a fruitful learning environment.

"Vodnikova Road in Ljubljana" - Slovenia, tells of a ground-breaking local initiative for a pedestrian and cyclist-friendly renovation of a road into the city that is the centre of a neighbourhood ${ }^{12}$ in an interview between Marko Peterlin and Matej Nikšič.

Providing a broader perspective, the practice story by Ged on tourism in rural areas in China shows how horizontal exchanges and shared learning experiences among researchers and practitioners from different countries can be fruitful and lessons learned transferable, but only under the condition of an established long-term engagement "where only by encouraging long-term processes, with the support of education and mutual learning through experimentation, can the barrier of disciplinarity be conquered. A long-term process requires funding and institutional support, which leads to the third challenge we want to raise awareness about: limited access to funding."

\section{Part IV: "Lesson Learned - Beyond Context"}

The nine case studies in Part II and the seven practice stories in Part III are also a key source of insight and reflection for the final part, Part IV, "Lesson Learned - Beyond Context." Here, Woiwode and Bina ask whether transdisciplinarity "changes everything." In their contribution, they critically reflect on the relationship between multi-, inter- and transdisciplinarity, complementing the aspects highlighted here and then exploring the possibility of a transformative potential.

Weber and Mennes deliver a reflection on how knowledge is integrated within inter- and transdisciplinary urban research from the perspective of the philosophy of science. This contribution again builds on the case studies and practice stories presented and is a post-reflection on the specific issue of knowledge integration.

Finally, Fokdal et al. draw lessons from the experience of the past four years working together as INTREPID and connect it with the global agenda for sustainable development by exploring the dimension of education of future generations for sustainable development (ESD), and articulating further the aspect of competences and dispositions, central to this book's framework (Chapter I.2). 


\section{Notes}

1 Wissenschaftlicher Beirat der Bundesregierung Globale Umweltveränderungen (WBGU) was founded in 1992 with the aim to evaluate, report and develop coping suggestions on climatic and environmental changes.

2 Urban sustainability encompasses the basic values of environmental quality, economic dynamics and social justice, and requires their application to areas including transportation, land use, urban form, architecture and building construction practices (Wheeler \& Beatley, 2009), and it is often equated with more compact, socially inclusive, better integrated and connected cities and territories that are resilient to climate change (UN-Habitat, 2014). In this context, by sustainable urban development we refer to environmental justice, economic improvement and social equity as reflected in evolving urban systems (i.e. buildings, towns, cities and their infrastructures).

3 See Chapter IV.3 in this volume.

4 The understanding of knowledge used here incorporates a diverse field of knowledge including systemic knowledge, aim- or orientation knowledge (Schäpke et al., 2017) and transformation knowledge (e.g. Schneidewind \& Singer-Brodowski, 2014). It further takes everyday experiential knowledge such as actionable knowledge into account (Forrest \& Wiek 2014; Schäpke et al., 2017). In a broader sense the urban knowledge arena also includes informal knowledge (Andersen, 2013, p. 9ff.). This broad perception of knowledge is essential to bridge the gap between urban research and practice, especially when viewed in the frame of the ambitious international agendas for urban sustainability, and the transformational drive uniting these and the science agenda.

5 See ESF (2012), Lyall et al. (2013) and Petts et al. (2008) for a critique.

6 For useful definitions of interdisciplinarity, the reader might also look at Blanchard and Vanderlinden (2010), Frodeman et al. (2010) and Lawrence (2004).

7 See Mistra Urban Futures, now Urban Futures, which was formed in 2010 as a programme and centre for knowledge and research on sustainable urban development (www.mistraurbanfutures.org/en) and recent outputs: Simon (2016); Simon et al. (2020).

8 See, for example, www.transdisciplinarity.ch, td-net or Hirsch Hadorn et al. (2008) for a definition.

9 Andersen and Atkinson (2013), Owens et al. (2006), Petts et al. (2008) and Simon et al. (2020) all discuss this.

10 Various levels of engagement have been defined between civil society and the state in participatory processes (e.g. Arnstein, 1969; Goethert, 2004). A common method of differentiating levels of participation as a continuum of influence in the decision-making process, from full control by planners or external experts to full control of the planning process by the community, is based on the "ladder of participation" proposed by Arnstein (1969). Hamdi and Goethert (1997) suggest not only levels but also stages of participation in planning and implementation.

11 And the four-year journey we have all been through together with the COST Action INTREPID.

12 See Institute for Spatial Policies (IPoP) "More than a Road to a City" (Več kot cesta do mesta), supported by the Municipality of Ljubljana, October 2018, and Facebook: Iniciativa uredimo Vodnikovo.

\section{References}

Andersen, H. T. (2013). Working Group 1: Characterisation of existing and future urban knowledge. In Nolmark, H., Muir, T., Andersen, H.T., Troeva, V., \& Schmeidler, K. Interim Report, cost action C20 Urban Knowledge Arena [accessed May 2017].

Andersen, H.T., \& Atkinson, R. (2013). Existing and future urban knowledge: Studies in the production and use of knowledge in urban contexts. In: Andersen, H.T., \& Atkinson, R. (Eds.). Production and use of urban knowledge: European experiences, pp. 1-15. Dordrecht: Springer.

Arnstein, S. (1969). A Ladder of Citizen Participation. JAIP, 35, 216-224.

Barry, A., \& Born, G. (Eds.). (2013). Interdisciplinarity, reconfigurations of the social and natural sciences. London: Routledge. 
Benz, A., \& Papadopoulous, Y. (2006). Introduction. Governance and democracy: concepts and key issues. In: Benz, A. \& Papadopoulous, Y. (Eds.). Governance and Democracy. London: Routledge.

Blanchard, A., \& Vanderlinden, J. P. (2010). Dissipating the fuzziness around interdisciplinarity: The case of climate change research. SAPIENS: Surveys and Perspectives Integrating Environment and Society, 3, 1-6.

Bradbury, H., \& Reason, P. (2003). Action Research. An opportunity for revitalizing research purpose and practices. Qualitative Social Work, 2(2), 155-175.

Bunders, J., \& Regeer, B. (2009). Knowledge co-creation: Interaction between science and society. A transdisciplinary approach to complex societal issues. Den Haag: Advisory Council for Spatial Planning, Nature and the Environment (RMNO).

Chakraborty, A. (2012). Recognizing uncertainty and linked decisions in public participation: A new framework for collaborative urban planning. Systems Research and Behavioral Science, 29, 131-148.

Chambers, R. (1998). Beyond "Whose reality counts?" New methods we now need? Studies in Cultures, Organizations and Societies, 4(2): 279-301.

Cooke, B., \& Kothari, U. (2001). The case for participation as tyranny. In: Cooke, B., \& Kothari, U. (Eds.). Participation: The new tyranny? New York: Zed Books.

Cornell, S., Berkhout, F., Tuinstra, W., Tàbara, J. D., Jäger, J., Chabay, I., Wit, B. D., Langlais, R., Mills, D., Moll, P., Otto, I. M., Petersen, A., Pohl, C., \& Kerkhoff, L. V. (2013). Opening up knowledge systems for better responses to global environmental change. Environmental Science and Policy, 28, 60-70.

Dobbs, R., Oppenheim, J., \& Thompson, F. (2012). Mobilizing for a resource revolution, McKinsey Global Institute (MGI), Sustainability \& Resource Productivity Practice.

Doucet, I., \& Janssens, N. (2011). Transdisciplinary knowledge production in architecture and urbanism: Towards hybrid modes of inquiry (Urban and landscape perspectives). Springer.

Durham DeCesaro, G., and Sharp, E. (2016). Ordinary wars: Doing transdisciplinary Research. Common Ground Publishing LLC. The Arts in Society, Champaign, Illinois

ESF. (2012). The good, the bad and the ugly: Understanding collaboration between the social sciences and the life sciences. European Science Foundation (ESF), Standing Committee for the Social Sciences (SCSS), Strategic Workshop Report. Available at http://archives.esf.org/uploads/media/TheGoodThe_ BadTheUgly2.pdf [accessed June 2020].

European Union (2016). Statistics on European Cities, Towns and Suburbs. Statistical Yearbook. Luxembourg: European Union.

Forrest, N., \& Wiek, A. (2015). Success factors and strategies for sustainability transitions of small-scale communities - evidence from cross-case analysis. Environmental Innovation and Societal Transitions, 17, 22-40.

Frodeman, R., Klein, J. T., \& Mitcham, C. (Eds.). (2010). The Oxford Handbook of Interdisciplinarity, Oxford: Oxford University Press.

Goethert, R. (2004). Planning with people - challenges to the paradigm. In: Herrle, P. \& Walther, U.-J. (Eds.). Socially inclusive cities. Berlin: Lit Verlag.

Hamdi, N., \& Goethert, R. (1997). Action planning for cities. Chichester: John Wiley \& Sons.

Healey, P. (1993). Planning through debate: The communicative turn in planning theory. In: Fischer, F., and Forester, J. (Eds.). The argumentative turn in policy and planning. Durham, NC/London: Duke University Press, 233-253.

Healey, P. (1997). Collaborative planning: Shaping places in fragmented societies. London: Macmillan.

Herrle, P., Ley, A., \& Fokdal, J. (Eds.). (2015). From local action to global networks: Housing the urban poor. London: Ashgate.

Hirsch Hadorn, G., Hoffmann-Riem, H., Biber-Klemm, S., Grossenbacher-Mansuy, W., Joye, D., Pohl, C., Wiesmann, U., \& Zemp, E. (Eds.). (2008). Handbook of transdisciplinary research. Springer.

Hoffmann-Riem, H., Biber-Klemm, S., Grossenbacher-Mansuy, W., Hadorn, G. H., Joye, D., Pohl, C., Wiesmann, U., \& Zemp, E. (2008). Introduction: Idea of the handbook. In: Hirsch Hadorn, G., HoffmannRiem, H., Biber-Klemm, S., Grossenbacher-Mansuy, W., Joye, D., Pohl, C., Wiesmann, U., \& Zemp, E. (Eds.). Handbook of transdisciplinary research. Springer, 3-18.

Huutoniemi, K., Klein, J. T., Bruun, H., \& Hukkinen, J. (2010). Analyzing interdisciplinarity: Typology and indicators. Research Policy, 39(1), 79-88. http://dx.doi.org/10.1016/j.respol.2009.09.011. 
ICSU \& ISSC (2015). Review of the Sustainable Development Goals: The science perspective. Paris: International Council for Science (ICSU).

Klein, J. T. (2010). The taxonomy of interdisciplinarity. In: Frodeman, R., Klein, J. T., \& Mitcham, C. (Eds.). Oxford handbook of interdisciplinarity. Oxford: Oxford University Press.

Klein, J. T., Grossenbacher-Mansuy, W., Häberli, R., Bill, A., Scholz, R. W., \& Welti, M. (Eds.). (2001). Transdisciplinarity: Joint problem solving among science, technology, and society. Basel: Birkhäuser.

Lang, D., Wiek, A., Bergmann, M., Stauffacher, M., Martens, P., Moll, P., Swilling, M., \& Thomas, C. (2012). Transdisciplinary research in sustainability science: Practice, principles and challenges. Sustainability Science, 7, 25-43.

Lawrence, R. J. (2004). Housing and health: From interdisciplinary principles to transdisciplinary research and practice. Futures, 36, 487-502.

Lowe, P., and Phillipson, J. (2009). Barriers to research collaboration across disciplines: Scientific paradigms and institutional practices. Environment and Planning A, 41(5), 1171.

Lyall, C., Bruce, A., Marsden, W., \& Meagher, L. R. (2013). The role of funding agencies in creating interdisciplinary knowledge. Science and Public Policy, 40(1), 62-71.

Lyall, C., Meagher, L. R., \& Bruce, A. (2015). A rose by any other name? Transdisciplinarity in the context of UK research policy. Futures, 65, 150-162.

Mendes, M. M., \& Sá, T. (2017). Interdisciplinary relations between social sciences and architecture: Tensions, ambiguities and complementarities. In: Mendes, M. M., Sá, T., \& Cabral, J. (Eds.). Architecture and the social sciences: Inter- and multidisciplinary approaches between society and space. Cham, Switzerland: Springer International Publishing, 33-50.

Mendes, M. M., Sá, T., \& Cabral, J. (Eds.). (2017). Architecture and the social sciences: Inter- and multidisciplinary approaches between society and space. Cham, Switzerland: Springer International Publishing.

Mosse, D. (2001). "People's knowledge", participation and patronage: Operations and representations in rural development. In: Cooke, B., \& Kothari, U. (Eds.). Participation: The new tyranny? New York: Zed Books.

New Economics Foundation. (2009). The great transition. Available at https://neweconomics.org/2009/10/ the-great-transition [accessed May 2019].

Owens, S., Petts, J., \& Bulkeley, H. (2006) Boundary work: Knowledge, policy, and the urban environment. Environment and Planning C, 24(5), 633.

Parodi, O., Ley, A., Fokdal, J., \& Seebach, A. (2018). Empfehlungen für die Förderung und Weiterentwicklung von Reallaboren. Erkenntnisse aus der Arbeit der BaWü-Labs. GAIA 29(S2), 178-179.

Petts, J., Owens, S., \& Bulkeley, H. (2008). Crossing boundaries: Interdisciplinarity in the context of urban environments. Geoforum, 39(2), 593-601.

Pohl, C., Rist, S., Zimmermann, A., Fry, P., Gurung, G., Schneider, F., Ifejika, S., Kiteme, B., Boillat, S., Serrano, E., Hadorn, G. H., \& Wiesmann, U. (2010). Researchers' roles in knowledge co-production: Experience from sustainability research in Kenya, Switzerland, Bolivia and Nepal. Science and Public Policy, 37, 267-281.

Polk, M. (2014). Achieving the promise of transdisciplinarity: A critical exploration of the relationship between transdisciplinary research and societal problem solving. Sustainability Science, 9, 439-451.

Polk, M. (2015). Transdisciplinary co-production: Designing and testing a transdisciplinary research framework for societal problem solving. Futures, 65, 110-122.

Polk, M. (2016). How to manage complexity: Co-producing knowledge for urban change. In: Co-production in action: Towards realising just cities. Gothenburg: Mistra Urban Futures.

Porter, A. L., \& Rafols, I. (2009) Is science becoming more interdisciplinary? Measuring and mapping six research fields over time. Scientometrics, 81(3), 719-745.

Roy, A. (2009). Civic governmentality: The politics of inclusion in Beirut and Mumbai. Antipode, 41, 159-179.

Sachs, J. D., Schmidt-Traub, G., Mazzucato, M., Messner, D., Nakicenovic, N., \& Rockström, J. (2019). Six transformations to achieve the Sustainable Development Goals. Nature Sustainability, 2, 805-814; DOI: 10.1038/s41893-019-0352-9.

Satterthwaite, D., \& Bartlett, S. (Eds.). (2016). Cities on a finite planet. London: Routledge. 
Schneidewind, U., \& Singer-Brodowski, M. (2014). Vom experimentellen Lernen um transformativen Experimentieren. In: Hollstein, B., Tänzer, S., \& Thumfart, A. (Eds.). Schlüsselelemente einer nachhaltigen Entwicklung: Haltungen, Bildug, Netzwerke. Zeitschrift für Wirtschafts- und Unternehmensethik, 16 (1), 10-23.

Scholz, R.W. et al. (2006). Transdisciplinary case studies as a means of sustainability learning: Historical framework and theory. International Journal of Sustainability in Higher Education, 7(3), 226-251.

Schäpke, N., Stelzer, F., Bergmann, M., Singer-Brodowski, M., Wanner, M., Caniglia, G., \& Lang, D. (2017). Reallabore im Context transformativer Forschung. Ansatzpunkte zur Konzeption und Einbettung in den internationalen Forschungsstand. (No. 1/2017). Leuphana Universität Lüneburg, Institut für Ethik und Transdisziplinäre Nachhaltigkeitsforschung.

Simon, D. (Ed.) (2016) Rethinking sustainable cities: Accessible, green and fair. Bristol: Policy Press.

Simon, D., Palmer, H., \& Riise, J. (2020). Comparative urban research from theory to practice: Co-production for sustainability. Bristol: Policy Press.

Sterling, S. (2004). Sustainable education re-envisioning learning and change. Foxhole, Devon, UK: Green Books for the Schumacher Society.

Stokols, D. (2014). Training the next generation of transdisciplinarians. In: O'Rourke, M. O., Crowley, S., Eigenbrode, S. D., \& Wulfhorst, J. D. (Eds.). Enhancing communication \& collaboration in interdisciplinary research. Los Angeles: Sage Publications.

UNDESA. (2012). Building a sustainable and desirable economy-in-society-in-nature. New York: United Nations Department of Economic and Social Affairs (UNDESA).

UNESCO \& ISSC. (2010). World social science report: Knowledge divides. United Nations Educational, Scientific and Cultural Organization (UNESCO)/International Social Science Council (ISSC).

UNGA (2015). Transforming our world: The 2030 Agenda for Sustainable Development. Geneva: UN General Assembly (UNGA). Resolution adopted by the General Assembly on 25 September 2015.

United Nations Human Settlement Programme (UN-Habitat). (2006). Enabling shelter strategies: Review of experience from two decades of implementation. Nairobi: UN-Habitat.

United Nations Human Settlement Programme (UN-Habitat). (2011). Housing the poor in African cities. Community-based organizations: The poor as agents of development. Quick guide. Nairobi: UN-Habitat, Cities Alliance.

United Nations Human Settlement Programme (UN-Habitat). (2014). The future we want. The city we need. United Nations Human Settlement Programme. Available at https://mirror.unhabitat.org/downloads/ docs/The\%20City\%20We\%20Need.pdf [accessed January 2020].

United Nations Human Settlement Programme (UN-Habitat). (2016). Habitat III: Draft New Urban Agenda, July 28th. Available at http://habitat3.org/the-new-urban-agenda [accessed September 2019].

United Nations Human Settlement Programme (UN-Habitat) \& Global Land Tool Network (GLTN). (2009). Not about us without us: Working with grassroots organisations in the land field. Nairobi: UN-Habitat and GLTN.

United Nations Human Settlement Programme (UN-Habitat) \& United Nations Economic and Social Commission for Asia and Pacific. (2008). Urbanization: The role the poor play in urban development. UNHabitat and UN-ESCAP.

Van De Bosch, S., \& Rotmans, J. (2008). Deepening, broadening and scaling up: A framework for steering transition experiments. Essay 02. Knowledge Centre for Sustainable System Innovations and Transitions. http://hdl.handle.net/1765/15812 [accessed 3 May 2020].

Van Rijnsoever, F. J., \& Hessels, L. K. (2011). Factors associated with disciplinary and interdisciplinary research collaboration. Research Policy, 40(3), 463-472.

WBGU. (2014). Sondergutachten Klimaschutz als Weltbürgerbewegung. Berlin: WBGU. Available at http:// www.wbgu.de/sondergutachten/sg-2014-klimaschutz/ [accessed 15 June 2017].

WBGU. (2016). Humanity on the move: Unlocking the transformative power of cities. [Online]. Flagship Report 2016, Advisory Council on Global Change (WBGU), Secretariat. Available at http://www.wbgu. de/en/fr2016 [accessed 01 August 2017]. 
Wernli, D., \& Darbellay, F. (2016). Interdisciplinarity and the 21st century research-intensive university, League of European Research Universities (LERU). Available at http://www.leru.org/files/publications/Interdisciplinarity_and_the_21st_century_research-intensive_university.pdf [accessed 22 December 2016].

Weszkalnys, G., \& Barry, A. (2014). Multiple environments: Accountability, integration and ontology. In: Barry, A., \& Born, G. (Eds.). Interdisciplinarity: Reconfigurations of the social and natural sciences. London and New York: Routledge, 178-208.

Wheeler, S. M., \& Beatley, T. (Eds.). (2009). The sustainable urban development reader. London: Routledge. 